\title{
Analysis of perceptual, psychological, and behavioral factors that affect the academic performance of education university students.
}

DOI: https://doi.org/10.1016/j.physbeh.2021.113497

\section{Authors}

Ana Isabel Beltrán-Velasco, Macarena Donoso-González, Vicente Javier Clemente-Suárez

\section{Abstract}

The aim of this study was the effect of different perceptual, psychological, and behavioural factors in the academic performance of university students. A total of 172 students ( $23.5 \pm 5.4$ years) were recruited. Physical activity patterns, nutritional habits, personality factors, perceptions of difficulty, expected grade, grade average, and academic performance of students were analyzed. No significant differences were found in physical activity levels in relation to academic performance. Significant differences were found in the agreeableness domain in relation to higher academic performance, higher perception of healthy diet and higher body mass index values. With these results we can conclude that university student with higher academic performance were characterized by higher levels of agreeableness, perception of healthy diet and body mass index.

\section{Keywords}

Stress, Personality, Psychology behavior, University students 